\title{
Battered Women: Victims or Survivors?
}

\author{
Anca Bejenaru ${ }^{1 *}$
}

${ }^{1}$ Lucian Blaga University of Sibiu, Department of Sociology and Social Work, 2-4 Lucian Blaga, 550169 Sibiu, Romania

KEYWORDS

Battered women

Recurrence

Shelters

Strategies of survival

\section{ABSTRACT}

From 1970, research into women's responses to marital violence became much more intense than ever before. Academic literature emphasizes two explanatory perspectives: of the woman as passive victim and of the woman who uses strategies to protect herself. The main goals of this study were to explore the effectiveness of personal strategies that women use to survive violence, the factors that influence the recurrence of violence, and the demand for shelter and the role of shelters in the process of recovery and healing. We interviewed eight battered women, from rural areas, all of whom had taken refuge in shelters, some of them several time. We identified a number of psychopathological consequences of domestic violence against women. Regardless of the severity of the attacks, the assumption that women are passive in face of violence doesn't hold water. Women's effort to survive violence is often hampered by inefficient response of rural police and the apathy of the community at large. The study concludes with suggestions for practice.

\section{Introduction}

Intimate partner violence is a phenomenon affecting a large number of women everywhere (WHO 2002, 2005). Many researches and analysis undertaken internationally highlight the devastating effects of this phenomenon on battered women's life (see Hamel and Nicholls 2007; Levendosky and Graham-Bermann 2001; Lloyd 1997; Chemtob and Carlson 2004; Tolman and Rosen 2001 etc.). There is little understanding of the

\footnotetext{
* Contact address: anca.bejenaru@ulbsibiu.ro (A. Bejenaru)
} 
reasons why women remain in an abusive relationship for long periods of time and why they return to the batterer after short periods of separation. Academic literature emphasizes two explanations: of the woman as victim, characterized by passive acceptance of victimization, and of the woman as survivor, who adopts active behaviour and uses a range of strategies for managing violence. If the first perspective seeks, even if not directly to blame the woman for recurrent victimization, the second perspective justifies her failure to interrupt the cycle of violence, by a mix of psychological, social and cultural factors, which hinder battered woman to solve the problem.

The purpose of this study was to explore personal strategies used by Romanian battered women, beneficiaries of shelters, some of them recurrent, to survive intimate partner abuse. The main goals were to explore the personal strategies that women use to survive violence and their effectiveness, the factors that influence the recurrence of violence and request for shelter and the role of shelters in the process of recovery and healing.

\section{Why using "battered women"?}

Domestic violence has a number of names: intimate partner violence, violence against women, women battering etc. Quite often the academic literature offers a blurred picture in this respect, many authors interchanging these concepts. For this study we have chosen to use the term "women battering" (derived the term "battered women"). More than the others, this term indicates severe forms of physical, sexual and psychological violence, that lead to intimidation, coercive control and domination of women (Denmark and Paludi 2007; Dasgupta 2002). It also suggests that violence is chronic or repetitive (Okun 1986; Walker 1986). This term is the most appropriate way to describe the situation of women who were interviewed for this study. 


\section{Battered women as victims}

Why does she stay? - is the question around which early investigations were focused and it has formulated the first theories that concentrated on women's response to violence. Initially, researchers took a psychopathological approach. Battered women were accused of masochism (Snell et al 1964) a form of sickness which itself provoked violence (Faulk 1974 ) is the first explanation. Other explanations were drawn from the consequences of violence. Learning helplessness theory (Walker 1978), battered woman syndrome (Walker 2000, 2009), post traumatic stress disorders (DSMIV) are theories that explain women's responses to battering, particularly through pathological feelings, accompanied by the loss of hope and a feeling of incapacity to deal with the situation caused by violence. The strong emotional ties between the woman and the batterer, supported by intermittent violence, and an imbalance of power in favour of the abuser, are other explanations offered by traumatic bonding theory (Dutton and Painter 1981). In the same sphere of development of pathological emotions to batterers, there is also the explanation offered by the Stockholm syndrome theory (Graham, Rawlings and Rigsby 1994).

The main critique we have is that these theories are unifactorial, concentrating primarily on internal psychological, mostly dysfunctional processes (Kelly, Gonzalez-Guarda and Taylor, 2011). These theories claim battered women are passive in relation to what it is happening. They adopt a critical view, blaming the women. In fact, women use a range of survival strategies for both themselves and their children. Moreover, Lempert emphasized that the apparent passivity is in fact a strategic mode of action undertaken in preservation of self, among other strategies adopted by women (1996: 281). In addition, none of these theories, considered separately, can explain the woman's decision to stay or leave the abusive relationship. Many factors contribute to this decision, and socio-cultural context, which is absent from previous theories, seems to be very important.

\section{Battered women as survivors}


The assumption that women are passive in face of violence was strongly countered in 1988 by Gondolf and Fisher. Studying 6612 battered women from 50 shelters in Texas, they formulated the theory of battered women as survivors. The basic assumption of this theory is that battered women are "active help seekers” (1988: 91). They are „survivors, in that they assertively and persistently attempt to do something about their abuse (...). The women contact a variety of help sources and forms of assistance. The help seeking seems to increase as the violence becomes more dangerous and incorrigible (1988: 93). The model implies more of a system failure than a failure on the part of the battered woman, when she remains entrapped in the abusive environment (1988: 38).

This theory does not deny the severe psychopathological effects that may be experienced by battered woman as a result of abuse, nor the fact that she may stay or return to the batterer: The lack of options, know-how and finances raises fears about trying to escape the batterer. The battered women may therefore attempt to change the batterer instead of attempting to leave (Browne 1997: 103).

The theory formulated by Fisher and Gondolf, clearly marked an important change of view on the battered women's behaviour, and also draws attention to the barriers that may influence women's capacity to respond properly in situations of violence.

\section{Strategies of surviving}

Davies et al. (1998) define personal strategies of surviving as seeking to prevent and respond to violence. The adoption of these strategies is generally based on three categories of resources: (a) personal resources, (b) informal resources, (c) formal resources (see Bowker 1983, Goodman et al. 2003). These strategies and resources will be detailed below.

Personal strategies for responding to violence: The first strategy that women adopt in a planned manner or simply from an instinct of preservation is self defence strategies when she tries to mitigate the effects of physical violence against them and their children. Davies et al (1998) identifies a range of actions in this regard: crouching, covering face, blocking strikes, wearing 
thick clothes, hiding sharp objects usually used by the abuser. Adopting these strategies may also have another purpose, namely to keep the violence invisible outside the conjugal home. In this respect Lempert (1996) considers that the batterer uses a number of strategies such as: assertions of privilege, controlled assaults, social isolation of female partners, restricting partner's communications, blaming the woman, denying the woman's point of view, false reconstruction of abusive actions.

The strategies of protection from physical harm may also target the children. Women use a range of techniques for their sake, such as: to send the children out of home, to sleep in children's bedroom to protect herself and her children, to feed the children early and put them to bed before her partner comes home, never leave the children alone with her partner, to involve the children in a lot of activities that take them away from home for periods of time, to put the children's room as far away as possible from her and her partner's bedroom (Davies et al. 1998: 81-82).

Other actions of this category are: blocking the batterer, especially by barricading in a room, or fighting back (Davies et al 1998, Dutton 2000).

Response strategies by informal support request include: asking others to intervene in the domestic environment: immediate family members, extended family, partner's family, friends, religions officials or parishioners, co-workers. In some cases, women use children to call for help from outside or to strike their partners. Fleeing from home, alone or with children, and taking shelter with relatives, neighbours, friends, is another common strategy of self-defence (Davies et al 1998, Dutton 2000).

Response strategies, by request of formal support include: intervention of authorized institutions (usually the police) or leaving the abusive environment and requesting help from authorized institutions: police, healthcare, social services, shelters, etc. (Davies et al 1998, Dutton 2000).

Strategies to prevent re-victimization: These strategies are also varied. Whether women decide to stay or to leave the abusive environment, studies show that once the violence has been recognized by others they adopt active strategies to prevent re-victimization. We present below a summary based 
on studies by Davies, Lyon, Monti-Catania 1998, Lempert 1996, Dutton 2000, Straus and Gelles 1988, Bowker, 1983). Some women who decide to remain in abusive environments adopt communication strategies with the batterer to identify what leads to violence and to obtain promises that the violence will not be repeated. Others encourage their partners to participate in counselling, and others try to develop personal resources to deal with the situation or to plan a possible separation from the batterer. Many women try to increase their economic resources (looking for a job, seeking a temporary shelter, saving money without the abuser's knowledge, etc.). Others take coercive action directed at the abuser by gathering evidence of violence: obtaining forensic proof, complaining to the police and social services etc. Some women initiate divorce proceedings which they suspend in order to threaten the abuser that they will follow through with them whenever he becomes violent again. There are also women who try to maintain a psychological and spiritual balance. For this purpose they go to their church and often ask for psychological and social counselling. They also develop their own social support network which they can call on if necessary.

Leaving the abusive environment to prevent re-victimization may be a temporary action (taking refuge in shelters or relatives, friends, neighbours) or permanent (separation and divorce).

\section{Leaving or staying: factors influencing decision making}

As shown above, the decision to leave the abusive environment is not simple for everyone. Many factors can become barriers to an effective response to violence. Grigsby and Hartman (1997) proposed a contextual and multifactorial model, called the barriers model in an attempt to present these factors. The authors place the battered woman in the centre of 4 concentric circles. Each circle represents a layer of barriers in the battered woman's experience that potentially impedes her safety. These layers include (1) barriers in the environment; (2) barriers due to family, socialization, and role expectations; (3) barriers from the psychological consequences of violence; and (4) barriers from childhood abuse/neglect issues Grigsby and Hartman (1997: 485-486). We will use the model proposed by Grigsby and Hartman for a research review. 
The economic factor is seen by many studies to be the main predictor of response that the woman will have in the violence (see the review compiled by Anderson and Sauders, 2003; Barnett, 2001) and must be understood from many perspectives. First, the economic dependence of woman on batterer will make it difficult for her to leave him (Kim and Grey 2008, Hamby 2008, Dutton 1996). Then there is evidence that repeated victimization obstructs women's abilities to find work, maintain employment, and use their wages to establish greater economic independence and safety (Bell and Moe, 2004). The impairment of women's economic capacity is effected many years after the violence occurs (Lindhorst, Oxford and Gillmore 2004).

Inadequate community support, meaning lack of response to the needs of the battered woman or encouraging her to remain in abusive environment and tolerating abuse, is another social factor that influences her response (Barnett 2001, Strube and Barbour, 1983). In other situations, community support is obstructed by battered women's self-isolation (Ptacek, 1999). There were several types of isolation identified by Davis, Taylor and Furniss (2001): physical, as in geographical; social, as in lack of friends and social networks; cultural, as in living in an alternate community; and emotional, because of shame and loss of initiative.

One of the most important factors which has great relevance to women's responses to violence, is the effectiveness of social, medical and legal services. Ptacek (1999) incriminates the indifference of powerful institutions to woman's suffering. Stark and Flitcraft (1988: 116-117) talk about a feeling of social entrapment, which is a response to a history of denial, minimization of their problems, and blame by those from they have sought support and protection, including police, doctors, social workers, and therapists.

The inappropriate attitude of practitioners, especially of the policemen, has often been incriminated. Even if they indicate an improvement in the police's response to the battered women, in a literature review, Straus and Gelles (1990) states that very often, police adopt attitudes and behaviours which inhibiting the help-seeker: by siding with the batterer, by adopting patriarchal and patronizing attitudes, by failing to refer 
battered women to the appropriate support services, by failing to file reports, and failing to adhere to prescribed policies and laws.

Churches' responses to battered women help who seek help were also studied, but the results on its effectiveness are not convergent. In a study conducted in 1992, Wood and McHugh (1994) identified that several clerical responses which included statements that placed the blame on the female. Shannon-Lewy and Dull (2005) sustained that cleric theological beliefs may hinder priests' ability to counsel victims, and the effectiveness of cleric ability to counsel victims varies greatly. One thing is certain: most clergy do not receive training for counselling and helping battered women (Rotunda et al. 2004; Strickland et al. 1998; Shannon-Lewy and Dull 2005).

Barriers due to family, socialization, and role expectations

Women's socialization in environments in which gender roles are rigidly defined, where the concept of masculinity is linked to toughness, male honour, or dominance and authority, where family violence is tolerate, and man is perceived as the "ownership" of women, can become a barrier to women finding safety strategies (Straus 1976; Heise 1998). Cultural pressures to keep problems in the family often prevent women from finding relief as well (Dasgusta 2007; Lempert 1996).

\section{Psychological barriers}

Studies show that many abused women are depressed, present increased anxiety and fear, have low self-esteem, have feelings of worthlessness and powerlessness, self-blame and medical and functional problems (Ptacek 1999, Orava, McLeod and Sharpe, 1996, Kim and Gray 2008, Clements et al. 2004, Dutton and Painter 1993, Barnett 2001). All of these are detrimental to efficient strategies for survival. Women often develop defence mechanisms including minimization, rationalization, denial and dissociation (Anderson 2008). Also many studies show that a large number of women live with the hope of change that prevents them to leave (Marden and Rice 1995, Painter and Dutton, 1985). Marden and Rice (1995) indicated that women maintain hope in four major dimensions: hope for 
change in their partner's behaviour, hope for survival, hope as something to cling to and hope that they will be able to control the situation.

\section{Barriers from childhood abuse/neglect issues}

The influence of these factors is not entirely clear. Research findings are not convergent. For instance, Gelles (1976) and more recently, Whitfield et al. (2003) show that among people who experienced physical or sexual abuse in childhood or who grew up with a battered mother, the risk of victimization and perpetration was increased. Kim and Gray (2008) have not identified any association between these factors and passive acceptance of violence by women.

Besides the factors we have already presented there are other factors that can be identified as having an influence on women's response to violence: the number of children, the severity and frequency of abuse (Horton and Johnson 1993, Gelles 1976), marital satisfaction and the victims' investment in the marriage (economic, emotional, temporal) (Rusbult 1980, 1983).

\section{Leaving and returning: factors influencing recurrence of violence}

The process of change for many battered women, including the possibly of leaving the relationship is usually lengthy, complex and unstable (Davies, Lyon and Monti-Catania 1998; Taylor and Davis 2006). Many authors found that the majority of battered women generally leave the abusive relationship for several times (between 5 and 8 times) an abusive relationship, before they leave permanently (Okun 1986; Campbell, Miller, Cardwell and Belknap 1994; Horton and Johnson 1993).

The reasons are various. Some are related to the batterer. As such, some express their regret, others make promises that violence will not be repeated, others promise to attend counselling (Griffin et al 2005; Okun 1986). Most reasons are related to woman's feelings toward batterer and her resources (emotional attachment to the abuser, fear that the abuse may escalate, lack of safety and protection, lack of money and housing) (Griffin et 
al 2005, WHO 2002, Anderson et al. 2003). To these, you can add pressures from others and various legal issues. (Griffin et al 2005).

Experts say that the repeated leaving and returning of the victim is a necessary process for disengagement and recovery from the abusive relationship (WHO 2002). This process includes struggling for survival, grieving, and searching for the meaning of violence (Landenburger 1998).

\section{Research question}

A recent presentation by policy makers which addresses the issue of shelters' effectiveness shows that battered women stay in shelters for long periods of time, return very often and become dependent on social services. The following quote is eloquent: The victims are all the same; they stay much more in shelters than they should and unfortunately don't start the independent life that theory says that should happen after benefiting support (policy maker) (Bejenaru and Rusu 2010).

The causes of recurrence have not been studied much in Romania, especially with regard to women from rural areas. The survival strategies that women adopt for surviving an abusive relationship are little known. We believe that such information would be useful to practitioners who work directly with battered women and for those who design and manage social, medical and/or forensic services to help them. Therefore, this study aims to answer to five research questions: How do battered women experience violence? Are they passive victims of violence or active help seeking? What are the strategies they adopt to survive? How effective are these strategies? And what is the role of shelters in the process of women's recovering and healing?

\section{Methods and procedures}

The technique used in data collection was semi-structured interview. The goal of this technique was to allow the respondent to develop their own narratives and in the mean time to maintain overall control of the interview via a semi-structured topic guide which covered areas that were considered important to the research question (see Bowling and Ebrahim, 2005). The guide was developed through a review of the literature. 
The interviews were audio taped. We processed the data by the classical method of content analysis: by a full transcription of the interviews and data standardization, by defining the main categories for analysis, by dividing the data into units of analysis, by coding and then, finally, analysing the data.

\section{Participants}

We used a purposive sample consisting of eight women who had been battered by their marital partners. Four women repeatedly took refuge in shelters. All eight women come from rural areas. Every woman had at least one child. Seven of them were in the shelter with their children and in one case the children remained with the woman's marital partner.

The women had a low or medium educational level. Only two women had completed high school, three had qualifications from vocational schools and three had finished middle school.

When we interviewed them, three of the women had a job, two of them had previously been for different periods of time, but had resigned or were fired, and three others had never worked in their lives.

\section{Data analysis}

Four major themes emerged from the interview: the experience of abuse (length of time, frequency, severity, forms of abuse and consequences), survival strategies and their effectiveness, factors that favoured the recurrence of violence, and the role of shelters in the process of "recovery" and "healing".

\section{The experience of battering}

According to Dutton (1999: 195), we can state that battering is more than a series of discrete events. For all women, the abuse had become chronic, with acute periods of physical violence and alleged periods of calm, but generally, accompanied by a diffuse psychological abuse. For most women, the violence started early in the history of marital relationship, in 
one case, it started even before marriage. The victims lived with their abusers from between four to 13 years, before applying for housing in shelters.

Physical violence was present in all of the eight cases. This had taken severe forms and was manifested repeatedly. The following confessions are eloquent in this respect:

I was beaten even two to three times a week. He tried several times strangling me. I had often bruises on the neck and face.

He broke my nose and eyes do not say... I always was bandaged even for two, three week at a time.

In three cases the violence affected children too:

The beating was a question of the day; he slapped me and the kids on the head, on our faces, he kicked the boy in the back... I was really afraid he had spina bifida [split spine]. He kept peeing on him until he was 7 years old.

In two other cases physical violence was exerted on the victim's other relatives (parents, siblings):

He pushed my father and he fell down. He had asthma, and he went into a coma, told a woman.

Psychological violence, manifested through insults, denigration, humiliation to the victim, accompanies, in each case, physical violence:

I here all the time: "you're faded», "you're ugly», "oh, I never seen someone more stupid than you».

Two women also report the lack of affection and the partners' indifference, even in calm moments:

I'm a character that puts very much heart in a relationship, and I wanted him to do the same, but he was very cold. This upset me a lot.

Economic abuse took various forms. Women reported the destruction of property by fire or hitting (five of eight) to the deprivation of earnings (two victims), all sorts of destructive behaviours:

On the pay day, he expected me at the factory and takes all my money on the grounds that I do not know how to manage it. When I need money, I had to ask him, and after buying the necessary things I had to bring the receipt to justify for what I spent that day. 
Two of them were not allowed to work by the abuser, and another was dismissed because of the scandals caused by her partner in the workplace.

Another form of abuse was the social isolation. Three of the eight women were forced to break their ties with their original family, and two others reported isolation from neighbours and friends. One woman says:

We argued a lot because he would not let me see my mother or my brothers. They do not live far from us; sometimes I saw them in the street, but I was not even allowed to greet them.

These acts of violence had negative consequences on women's physical and mental health. The most frequently stated effects were digestive and sleep disorders, excessive consumption of tobacco, irritability, withdrawal, depression. We give some examples below:

There were nights when I dreamed that he beat me and as he tortured me.

Another woman reports:

In four years of marriage I was losing $20 \mathrm{~kg}$. I barely stood up, I was so weak... I suffered lot. He beat me and I didn't eat, I smoked a lot, and so I was getting weaker and weaker.

Indirectly, violence had a negative impact on the women's capacity to work. Women claim decreases of efficiency in domestic work and / or at the workplace.

\section{Strategies for survival}

Data obtained from interviews led us to reject the presumed passivity of women in the face of abuse. Each case revealed a range of individual strategies for survival in the face of violence and active attempts to prevent re-victimization. We mention that the battered women who adopted active survival strategies including those who experienced depression, withdrawal and even self-blame. Below, we give a summary of them.

Staying in abusive environment - Strategies for responding to violence

Generally, being physically weaker prevents women to protect themselves against physical violence. Most of them reported ecchymosis to 
the face, neck, hands caused by violence (see previous section), despite attempts at the self defence. Only one victim reported that she fought back:

Then I fought with him because I couldn't stay anymore and he brought the axe into the house, he lifted it above my head and said: right now I'm going to kill you. I succeeded in pushing him away, I don't know how and I threw him out of the house.

Children are habitually involved in violence. In two cases the children were physically abused, too. In other cases, children were passive witnesses to or were involved in acts of violence, in order to protect their mothers, or by interposing themselves between their mother and the batterer, or by asking for help outside the house (from relatives or neighbours):

When he hit me, the child started to cry, he came to me and took me in his arms and told him to leave his mammy alone, do not hit his mammy anymore.

The child ran to his godmother, and he called her to come to get me out of his hands. He [the batterer] is ashamed of her.

Six of the eight victims called the rural police, some of them repeatedly. In all these cases police intervention was considered inefficient. The women complained many times. For example, three victims complained that the measures taken by the rural police, such as drafting of statements, or fining the abuser had negative consequences because the abuse escalated or was an extra drain on the family budget:

After they [the rural police] admonished him, he beat me even harder, said a woman.

Another said:

They came and gave him a fine, which I paid from the children's allowance.

Three other women complained that the police did not take any measures:

He [the police] came hours later and didn't find him at home, said one woman.

Even more, one woman was "counselled" to return home, because she could not escape her batterer:

They intervened once when I was beaten badly and I left to my daddy. And they told me: "Do it again and get the hell home because you can't get rid of him anyway and you cannot make peace with him. Get in the 
cart, take your child and go home because he won't calm down and you can't get away of him."

Two women who have called the police, expressed lack of confidence in the police actions, which was nourished by the negative experience of relatives:

They do not help with anything. My mother was beaten for years and they did not move a finger, said one of the victims.

Two victims sought help by ringing the emergency phone number at The General Directorate for Social Work and Child Protection. They received little or no help: either the call was made outside office hours or the women were given counselling over the phone and didn't consider it effective.

Staying in abusive environment - Strategies to prevent abuse

Five of the battered women reported using communication with the batterer during periods of calm as a survival strategy. In two cases, the communication did not lead to any results. The partner refused to take any blame for his violence. Instead, in these cases, the abusers blamed the battered women. In three other cases, the battered women reported that their partners apologized and promised that they would not batter them again. But they did not respect their promises:

We were talking, and he felt sorry for what he had done... after we talked, he did it again.

In four of the eight cases, the partners were asked either by the victim or by practitioners to attend counselling. None of the abusers accepted.

Expanding their social resources by communicating with people outside their household is another strategy that helps the battered women psychologically, morally, and in her effort to find solutions to prevent domestic violence.

Communication with their original family: Six of the eight victims said that their families knew about their situation. The other two women had not communicated with their own family, because they weren't in touch with them or because they did not want them to know what was going on. The six women who did communicate with their own families about the violence they suffered did not always receive any support. Thus, two of the women said that they were treated with understanding and emotional support from 
the families of origin, but the family could not do more because of limited economic resources they benefit. Two women claimed that, in addition to emotional support, they received of economic support from family, whenever possible. In two other cases, the family did not show any empathy and understanding of the situation. Moreover both were advised to remain with the abusers because children should be raised with a father and woman must suffer.

Asked if their neighbours helped, the majority responded: No one wants to get involved! Two of them benefited from temporary refuge with neighbours.

It is interesting to note that most do not have friends, either because they changed their address by moving with their husbands or because their husbands isolated them after marriage.

Help from the church: Five of the battered women are Orthodox Christians; three belong to the Pentecostal Church. We identified major differences between the two groups. Among the Orthodox women, only one requested help from the church, namely from the priest, and the experience did not help her: The next day the whole village knew my problem, she said. Instead, all three Pentecostal women were supported by the church in different ways: through spiritual support, temporary accommodation, material financial support and information about shelters. However, rigid interpretation of religious values by the family may affect women's safety. For instance, a woman stated that:

Adultery is the only reason that the Bible allows you to leave home... Because God said so: "to love your husband for better or for worse". So I had to accept it ... less than adultery... The shelter where we are now is Christian and I am Christian and I wouldn't have gone elsewhere.

Five of the eight women sought help from the Institute of Forensic Medicine, in order to obtain a forensic certificate. Most women justified the need for these certificates to prove violence in order to obtain custody of the children in case of divorce and / or to request housing in public shelters. The cost of a forensic certificate proved to be a burden for them. For instance a woman said:

I had the money that my mother gave me on my birthday, and with that money I obtain a forensic certificate that my boss kept it at work so my husband wouldn't find it. 
Other resources accessed by battered women included Social Services in local councils (2 women), the General Directorate of Social Work and Child Protection (GDSWCP) (3 women).

\section{Leaving the abusive environment}

Flee from home occurs frequently when the violence escalates. Most women have lost count of the number of times they have fled to relatives, neighbours or friends. Two women did not have anywhere to go. For them, fleeing means taking refuge in the garden or on the streets until they estimate that the batterer calmed down or went to sleep. The women often planned how they would flee. One said:

I always keep the key in the pocket to be able to run ... and another said: When he was late from work we expected to come home drunk and make a scandal. Then we dressed in our better clothes so to be able to run out the door if necessary.

Hosting in shelters. During the period of our research, all eight women were in shelters. Four of them were there for the first time in shelter; the other four for the second or third time.

Most of them say that they sought help from shelters, as soon as they found out of that they existed. The majority stated that they were "lucky" that they succeeded to benefit from the services provided by the shelters. They say the shelters are "too little known" and "have few places." Most have heard about this service from their workplace, the municipal police, church (the Pentecostal women) or on the Internet. In any case, the information did not come from the rural police, although six women sought help from them.

Access to these services was not easy. It is either based on forensicmedical certificates that prove the abuse or based on social inquiry. One problem we identified was that these shelters do not take in battered women in emergencies. Most of the women we interviewed sought help from relatives or friends at least a day or two, before they were allowed into the shelter.

Recurrent hosting was possible only in private shelters. The policy in public shelters is that victims may stay only once. 


\section{Factors that favour the recurrence of violence}

Of the eight battered women, three returned to the marital partner after they received shelter once. There were many factors that led them to return to their abusers. Firstly, all the women reported lack of alternatives, due to lack of economic resources and housing; each of them also said that they had decided "to give [the batterer] another chance". This chance was given for various reasons: the partner has expressed regret for what he did and the woman still had feelings for him, or because of external pressure (from relatives or professionals). The case of a woman raised in an institutional care until the age of 18 was interesting. Her reason for returning to her husband was because she did want to lose the only family she has ever had.

One of the recurrent beneficiaries filed for divorce and attempted the separation from her abusive partner, after the first time she left the shelter. Financial problems and threats from the batterer, which focused particularly on their children, led her seek shelter again:

I almost succeeded... almost half of year... I worked, but with my salary, I couldn't manage the rent, and the kindergarten fee and my big debts. Besides, he found out where we lived and started to come more and more often to our place and to threaten us...

This case indicates the need for support and monitoring women for a while, after they left the shelters so they manage to have an independent life.

It has to be said that the women who take refuge in one shelter tend to return more often to their abusive partners. Three of the recurrent beneficiaries are from one shelter, and just one is from the other. These two shelters have different practices. In the shelter from which more women return to their abusers, the time allowed for shelter is shorter (six weeks to six months), the atmosphere in the shelter is less collaborative between women, and most have no plans / alternatives for the future.

I do not know how long I can stay here. I do not know what to do. I do not know where I will go. I do not know how I will cope. These phrases describe best the victim's state.

All the victims filed for divorce. Three of them decided to end the relation with the batterer (they were recurrent beneficiaries) one of them (in 
the shelter for the first time) suspended the action with the intention of returning home. She hopes that she "gave her husband a good lesson".

In the other shelter, most of the women who took refuge belong to the Pentecostal religion. They live together sharing their daily tasks and giving each other support in raising their children. The period they may spend in the shelter is not fixed (it can be up to 2 years if necessary). The women are encouraged to find a job, achieve economic independence, before leaving the shelter. We identified one case of recurrence, but note that the woman in question had entered a public shelter and had sought refuge for the first time. All of them filed for divorce or are already divorced.

\section{Shelters role in the process of "recovery" and "healing"}

All of the women stated that they were satisfied with the services the shelters provided, whether they were public or private. During their stay in these shelters women received everything they needed.

First material benefits. Because we came only with the clothes we were wearing. In the meanwhile the clothes became smaller. The kids grew up as from the water. They grew up very well here. What to say. Everything... from clothes to shoes... everything... hygiene products, everything... counselling...

The main benefit was psychological recovery.

We were hunted, we were afraid, I was nervous; I felt that I no longer resist, a woman said.

These were the main expressions that victims used to describe their initial state of mind when they arrive in the shelters:

I was in great need to talk to someone and to be listened... here we received social counselling. I went to a psychologist too. The foundation paid for me and the kids. There's no psychologist here, but I went to one; and to the doctor as well. I went and they paid. But the social counselling was very helpful.

Time spent in shelters has brought much peace of mind and a different attitude to violence. Most say they will not accept any form of violence. This is mainly why they returned to the shelters. The shelters have become a "safety net" in case they are battered again. 
I've changed. I won't accept it anymore... I won't let him hit me now. I left it again [she left home second time]. It was easier because I knew how. When I left for the first time, they assured me that they would always let me in ... and they did.

The women who went to public shelters and were told they could not return a second time consider this practice to be inappropriate.

\section{Conclusions}

Analyzing the data from the interviews and relating them to the literature, we have identified a number of psychopathological consequences of women battering. Regardless of their severity and consequences, we cannot sustain the theory that women are passive in face of domestic violence. Moreover, our findings converge with those of Gondolf and Fisher (1988), namely, that as the violence increases, women become more determined to seek help. None of them reached the shelters by chance. Each of them sought help for a long time.

The reasons why women remain in abusive relationships for long periods are rather socio-cultural. A low level of education, economic dependence and concentration on domestic work, lack of social services to prevent and combat violence in rural areas, the inadequate reaction of competent institutions: political, communal council, the churches (at least the Orthodox Church), are factors that cause women to stay in abusive environments for long periods of time.

If women find support and shelter with difficulty, why are they going back to their batterers? The results primarily indicate a lack of alternatives and ensuring their own subsistence. Women who received shelter for longer periods of time, until they manage to gain their independence were less likely to return to the abuser.

It is therefore important for practitioners to note that the recovery from violence is a long process. Women need a period for healing, and time to gain economic, and social independence. Even when she leaves the shelter to try to reach an independent life, a woman needs time for monitoring and support, to avoid returning to the shelter, and relapsing into a state of dependence. 
For those who choose, to return to the abuser after a brief period of refuge, shelters must remain "a safety net" in case of recurrence of violence.

Regardless of women's choice to return or to separate the abuser, a shelter is useful: it can assist the survivor in her relocation plans.

In rural communities, the study shows a lack of support services. The police did not provide a resource for battered women. Our study indicates a great need for the training of rural police officers to act impartially in cases of violence and to be able to offer adequate information regarding battered women's rights and their alternatives, if they decide to leave their batterers.

Even if they are only designed to provide basic services, social services in communal councils can help to prevent violence by offering information and social counselling.

\section{Limitations}

It is important to recognize some of the limitations of this study. First, the findings cannot be generalized due to the small size and relative homogeneity of samples. All the women we interviewed came from rural areas. The study only managed to capture the perspective of those who sought hosting in shelters. Second, the data were collected retrospectively; therefore they may be unreliable because of the selectivity of memory and changing attitudes to violence, once the women had taken shelter.

\section{Acknowledgements}

The paper was partially supported through the EU program Daphne III, grant number: JLS/2007/ DAP-1/058 30-CE-0227730/00-44, project title: 'A Comparative Analysis of Community Focused Initiatives Aimed at Supporting Women, Children and Young People Who Have Been the Focus of Violence, Exploitation or Trafficking in three regions of the United Kingdom, Germany and Romania'.

\section{References:}

American Psychiatric Association. 2000. Posttraumatic stress disorders. In Diagnostic and Statistical Manual of Mental Disorders DSM-IV-TR (4th edition), 838. Arlington: American Psychiatric Publication. 
Anderson, Deborah K. and Daniel G. Saunders. 2003. Leaving an abusive partner: An empirical review of predictors, the process of leaving, and psychological well-being. Trauma, Violence and Abuse 4 (2): 163191.

Anderson, Kristin L. 2008. Is Partner Violence Worse in the Context of Control? Journal of Marriage and Family 70 (5): 1157-1168.

Anderson, Michael A., Paulette Marie Gillig, Marilyn Sitaker, Kathy McCloskey, Kathleen Malloy and Nancy Grigsby. 2003. Why doesn't she just leave?: A descriptive study of victim reported impediments to her safety. Journal of Family Violence 18 (3): 151-155.

Barnett, Ola W. 2001. Why Battered Women Do Not Leave (Part 2): External Inhibiting Factors-Social Support and Internal Inhibiting Factors. Trauma, Violence E Abuse 2 (1): 3-35.

Bejenaru, Anca and Horațiu Rusu. 2010. Violența domestică: studiu de caz asupra furnizorilor şi beneficiarilor de servicii sociale din județul Sibiu. Paper presented at the 2010 Annual Conference of the Sociology and Social Work Department of the "Lucian Blaga" University of Sibiu, October 15-16, Sibiu, România.

Bowker, Lee H. 1983. Beating wife beating. Lexington, MA: Lexington Books.

Carter, Simon and Lesley Henderson. 2005. Approaches to qualitative data collection in social science. In Handbook of health research methods: investigation, measurement and analysis, eds. Ann Bowling and Shah Ebrahim, 215-230. Maidenhead: Open University Press.

Browne, Angela. 1997. Recognizing the Strengths of Battered Women. In Assessing woman battering in mental health services, ed. Edward W. Gondolf. Thousand Oaks: Sage.

Campbell, Jacquelyn C., Paul Miller, Mary M. Cardwell and Ruth A. Belknap. 1994. Relationship status of battered women over time. Journal of Family Violence 9 (2): 99-111.

Chemtob, Claude M. and John G. Carlson. 2004. Psychological effects of domestic violence on children and their mothers. International Journal of Stress Management 11 (3): 209-226.

Clements, Caroline, Caryn Sabourin and Lorinda Spiby. 2004. Dysphoria and Hopelessness Following Battering: The Role of Perceived Control, Coping, and Self-Esteem. Journal of Family Violence 19 (1): 2536.

Dasgupta, Shamita D. 2002. A framework for understanding women's use of nonlethal violence in intimate heterosexual relationships. Violence Against Women 8 (11): 1364-1389.

Davies, Jill M., Eleanor Lyon and Diane Monti-Catania. 1998. Safety Planning with Battered Women. London: Sage.

Davis, Kierrynn and Beverley Taylor. 2006. Stories of resistance and healing in the process of leaving abusive relationships. Contemporary Nurse 21 (2): 199-208. 
Davis, Kierrynn, Beverley Taylor and Di Furniss. 2001. Narrative accounts of tracking the rural domestic violence survivors' journey: A feminist approach. Health Care for Women International 22 (4): 333-337.

Dutton, Donald G. and Susan L. Painter. 1993. Emotional attachments in abusive relationships: A test of traumatic bonding theory. Violence and Victims 8 (2): 105-120.

Dutton, Donald G. and Susan L. Painter. 1981. Traumatic Bonding: The development of emotional attachments in battered women and other relationships of intermittent abuse. Victimology: an International Journal 6 (1-4): 139-155.

Dutton, Mary Ann. 2000. Empowering and Healing the Battered Woman. A Model for Assessment and Intervention. New York: Springer.

Dutton, Mary Ann. 1996. Battered women's strategic response to violence: The role of context. In Future interventions with battered women and their families, eds. Jeffrey L. Edleson and Zvi C. Eisikovits, 105-124. Thousand Oaks, CA: Sage Publications.

Faulk, M. 1974. Men who assault their wives. Medicine, Science and the Law 14 (3): 180-183.

Gelles Richard J. and Murray A. Straus. 1990. Physical violence in American families. New Brunswick, NJ: Transaction Publishers.

Gelles Richard J. and Murray A. Straus. 1988. Intimate violence: The definitive study of the causes, and consequences of abuse in the American family. New York: Simon \& Schuster.

Gelles, Richard J. 1976. Abused Wives: Why Do They Stay. Journal of Marriage and Family 38 (4): 659-668.

Gondolf, W. Edward and Ellen R. Fisher. 1988. Battered Women as Survivors: An alternative to treating learned helplessness. Massachusetts: Lexington Books.

Goodman, Lisa, Mary-Ann Dutton, Kevin Weinfurt and Sarah Cook. 2003. The Intimate Partner Violence Strategies. Development and Application. Violence against Women 9 (2): 163-186.

Graham, Dee L. R., Edna I. Rawlings and Roberta K. Rigsby. 1994. Loving to Survive: Sexual Terror, Mens Violence and Women's Lives. London: New York University Press.

Grigsby, Nancy and Brenda R. Hartman, 1997. The Barriers Model: An integrated strategy for intervention with battered women. Psychotherapy: Theory, Research, Practice 34 (4): 485-497.

Hamby, Sherry. 2008. The path of helpseeking: perceptions of law enforcement among american Indian victims of sexual assault. Journal of prevention $\mathcal{E}$ intervention in the community 36 (1-2): 89-104.

Hamel, John and Tonia L. Nicholls. 2007. Family interventions in domestic violence: A handbook of gender-inclusive theory and treatment. New York: Springer. 
Heise, Lori L. 1998. Violence against women: An integrated ecological framework. Violence Against Women 4 (3): 262-290.

Horton, Anne L. and Barry L. Johnson. 1993. Profile and strategies of women who have ended abuse. Families in Society 74 (8): 481-492

Kelly, Ursula A., Rosa M. Gonzalez-Guarda and Janette Taylor. 2011. Theories of Intimate Partner Violence. In Family Violence and Nursing Practice (2nd edition), eds. Janice Humphreys and Jacquelyn C. Campbell. New York: Springer.

Kim, Jinseok and Karen A Gray. 2008. Leave or stay?: Battered women's decision after intimate partner violence. Journal of Interpersonal Violence 23 (10): 1465-1482.

Landenburger, Karen M. 1998. The dynamics of leaving and recovering from an abusive relationship. Journal of Obstetric, Gynecologic, and Neonatal Nursing 27 (6): 700-706.

Lempert, Lora. 1996. Women's strategies for survival: Developing agency in abusive relationships. Journal of Family Violence 11 (3): 269-289;

Levendosky, Alytia A. and Sandra A. Graham-Bermann. 2001. Parenting in battered women: The effects of domestic violence on women and children. Journal of Family Violence 16 (2): 171-192.

Lindhorst Taryn, Monica Oxford and Mary Rogers Gillmore. 2007. Longitudinal Effects of Domestic Violence on Employment and Welfare Outcomes. Journal of Interpersonal Violence 22 (7): 812-828.

Lloyd, Susan. 1997. The effects of domestic violence on women's employment. Law and Policy 19 (2): 139-167.

Marden, Mary and Michael J. Rice. 1995. The use of hope as a coping mechanism in abused women. Journal of Holistic Nursing 13 (1): 70-82.

Moe, Angela M. and Myrtle P. Bell. 2004. Abject economics: The effects of battering and violence on women's work and employability. Violence Against Women 10 (1): 29-55.

Okun, Lewis. 1986. Woman abuse: Facts replacing myths. Albany: States University of New York Press.

Orava, Tammy A., Peter J. McLeod and Donald Sharpe. 1996. Perceptions of control, depressive symptomatology, and self-esteem of women in transition from abusive relationships. Journal of Family Violence 11 (2): 167-186.

Painter, Susan L. and Don Dutton. 1985. Patterns of emotional bonding in battered women. International Journal of Women's Studies 8 (4): 363375.

Ptacek, James. 1999. Battered Women in the Courtroom: The Power of Judicial Responses. Boston: Northeastern University Press.

Rhodes, Nancy R. and Eva B. Mckenzie. 1998. Why do battered women stay? Three decades of research. Aggression and Violent Behavior 3 (4): 391-406. 
Rotunda, Rob J., Gail Williamson and Michelle Penfold. 2004. Clergy response to domestic violence: A preliminary survey of clergy members, victims, and batterers. Pastoral Psychology 52 (4): 353-365.

Rusbult, Caryl E. 1983. A longitudinal test of the investment model: The development (and deterioration) of satisfaction and commitment in heterosexual involvements. Journal of Personality and Social Psychology 45 (1): 101-117.

Rusbult, Caryl E. 1980. Commitment and satisfaction in romantic associations: A test of the investment model. Journal of Experimental Social Psychology 16 (2): 172-186.

Schechter, Susan. 1982. Women and male violence: the visions and struggles of the battered women's movement. Boston: South End Press.

Shannon-Lewy, Colleen and Valerie T. Dull. 2005. The response of christian clergy to domestic violence: Help or hindrance? Aggression and Violent Behavior 10 (6): 647 - 659.

Snell, John E., Richard J. Rosenwald and Ames Robey. 1964. The wifebeater's wife: A study of family interaction. Archives of General Psychiatry 11 (2): 107-113.

Stark, Evan and Anne H. Flitcraft. 1988. Women and Children at Risk: A Feminist Perspective on Child Abuse. International Journal of Health Services 18 (1): 97 - 118.

Straus, Murray A. 1976. Sexual inequality, cultural norms, and wife-beating. In Victims and society, ed. Emilio C. Viano, 543-559. Washington: Visage Press.

Strickland, George A., Kathleen J. Welshimer, Paul D. Sarvela. 1998. Clergy perspectives and practices regarding intimate violence: A rural view. The Journal of Rural Health 14 (4): 305-311.

Strube, Michael J. and Linda S. Barbour. 1983. The decision to leave an abusive relationship: Economic dependence and psychological commitment. Journal of Marriage and the Family 45 (4): 785-793.

Tolman, Richard M. and Daniel Rosen. 2001. Domestic Violence in the Lives of Women Receiving Welfare Mental Health, Substance Dependence, and Economic Well-Being. Violence Against Women 7 (2): 141-158.

Walker, Lenore E. 1978. Treatment alternatives for battered women. In The victimization of women, eds. Jane Roberts Chapman and Margaret Jane Gates, 143-174. Beverly Hills: Sage.

Walker, Lenore E. 2009. The battered woman syndrome (3rd edition). New York, NY: Springer Publishing.

Walker, Lenore E. 1986. Battered women's shelters and work with battered lesbians. In Naming the violence: Speaking out about lesbian battering, ed. Kerry Lobel, 73-76. Seattle: Seal Press.

Whitfield, Charles L., Robert F. Anda, Shanta R. Dube and Vincent J. Felitti. 2003. Violent Childhood Experiences and the Risk of Intimate Partner 
A. Bejenaru - Battered Women: Victims or Survivors?

Violence in Adults - Assessment in a Large Health Maintenance Organisation. Journal of Interpersonal Violence 18 (2): 166-185.

Wood, Alberta D. and Maureen C. McHugh. 1994. Woman Battering: The Response of the Clergy. Pastoral Psychology 42 (3): 185-96. 